\title{
THE SEASONAL VARIATION IN THE CELLULOSE CONTENT OF THE COMMON SCOTTISH LAMINARIACEAE AND FUCACEAE
}

\author{
By W. A. P. Black, B.Sc., Ph.D., F.R.I.C. \\ Scottish Seaweed Research Association, Musselburgh
}

(Text-figs. I-6)

\section{INTRODUCTION}

Algal cellulose appears to have been relatively little studied and there is no information as to its seasonal variation in the brown marine algae. A study of the literature reveals numerous contradictions. In 1884, Stanford indicated in a report on alginic acid that he had obtained pure cellulose representing IO-I $5 \%$ of the air-dried plant.

Kylin (I915) showed that algal cellulose gave the characteristic colour reaction with iodine and sulphuric acid. He boiled the material in turn with $\mathrm{I} \cdot 25 \%$ sulphuric acid and I.25\% sodium hydroxide and called the insoluble residue cellulose.

In 1926, Atsuki \& Tomodo obtained a crude fibre figure of $6 \%$ for Laminaria saccharina, but stated that the greater part of the crude fibre of the laminarias consisted of the hemicelluloses and that there was so far no evidence of the normal cellulose.

Ricard (I93I) removed the alginic acid with sodium carbonate, then treated the residue with dilute boiling solutions of sulphuric acid and potassium hydroxide. The hydrolysis of the residual material with sulphuric acid gave only traces of reducing sugars, and the author did not regard it as cellulose but called it algulose. L. flexicaulis contained $4 \cdot 3-7 \cdot 6 \%$ of this material and L. saccharina $2 \cdot 8-10 \cdot 9 \%$.

Dillon \& O'Tuama (1935), however, isolated cellulose from the brown algae. The residue after the removal of alginic acid with dilute ammonia was treated with dilute hydrochloric acid and then several times with boiling $5 \%$ sodium hydroxide. It was finally washed with alcohol and ether, and was shown to have the properties of cellulose. On hydrolysis with hydrochloric acid it gave glucose characterized by the isolation of the glucosazone, and with carbon disulphide it formed a viscose resembling the viscose from ordinary cellulose. They also prepared acetylated and methylated compounds with properties similar to those of the corresponding derivatives of ordinary cellulose. 
Russel-Wells (I934) determined the crude fibre content of various algae and showed by its solubility in cuprammonium hydroxide and by its acetate that this fibre was cellulose.

Viel (1939) carried out a systematic study of the celluloses from Fucus vesiculosus $(2 \cdot 10 \%), F$. serratus $(2 \cdot 8 \mathrm{r} \%)$, Laminaria saccharina $(6 \cdot 9 \%)$ and L. cloustoni $(5 \cdot 04 \%)$. Analysis showed the carbon-hydrogen percentages to be remarkably similar and in agreement with $\left(\mathrm{C}_{6} \mathrm{H}_{10} \mathrm{O}_{5}\right)_{n}$. Hydrolysis gave $90 \%$ glucose, while thermal fractionation of the products of pyrogenation gave graphs comparable with those of previously studied vegetable celluloses.

Recent work by Percival \& Ross (1949) has shown conclusively that algal cellulose is essentially the same as cotton cellulose. Hydrolysis with $72 \%$ sulphuric acid gave only D-glucose. Cellobiose octa-acetate was prepared by acetolysis indicating the presence of $\mathrm{I}: 4-\beta$-linkages. Determinations by periodate oxidations indicated a chain length of 160 units, but the original cellulose was no doubt degraded during isolation. Finally, X-ray diagrams of algal cellulose showed the characteristic pattern of normal cellulose.

\section{EXPERIMENTAL}

The samples analysed were those taken in 1946 and previously reported by the writer (1948 a, $b$, 1949). The cellulose was estimated as follows.

Ground seaweed ( $2 \mathrm{~g}$.) was boiled under reflux with sulphuric acid ( $200 \mathrm{ml}$., $\mathrm{I} \cdot 25 \%$ ) for $30 \mathrm{~min}$., filtered by suction through a $\mathrm{I} \times 2$ Gallenkamp sintered glass crucible, washed free from acid with water, and the residue boiled with sodium hydroxide ( $200 \mathrm{ml}$., $\mathrm{I} \cdot 25 \%$ ). After boiling in this way for $30 \mathrm{~min}$., the solution was filtered through the $I \times 2$ crucible and washed with water. The residue was removed from the crucible and kept overnight in chlorine water (I00 ml. saturated), filtered on a weighed hardened paper, washed free from chlorine and washed on the filter with hot sodium hydroxide solution $(50 \mathrm{ml} . \mathrm{N} / \mathrm{ro})$. The residue was washed with water until free from alkali and finally with alcohol and ether, and then dried at $50^{\circ}$ for $\mathrm{Io}$ min. to give a white product which was weighed.

When applied to Fucus spp. the residue after treatment with boiling sodium hydroxide and chlorine water was often slimy and difficult to filter, and separation by centrifuging was necessary.

The results are given in Figs. I-6.

\section{Discussion of Results}

\section{General}

Very little is known regarding the structure of the cell wall of the Phaeophyceae. Fritsch (1945) concludes that it consists of pectic substances with a layer giving the reactions of cellulose adjacent to the protoplast. In the brown algae the pectic substance is no doubt alginic acid which, with its long 
chain structure, will give flexibility to the plant. To withstand wave-action such a structure is probably reinforced with cellulose, and the results of this investigation show that the cellulose content increases with the depth of immersion, when additional strength is required by the plant.

Very little is known, also, regarding the metabolism of the brown algae, but in the absence of any reducing sugars, it would appear that mannitol is probably the primary product of photosynthesis. In I933, Khouvine showed that cellulose could be synthesized from mannitol by Acetobacter xylinum, and quite independently Barsha \& Hibbert (I934) obtained the same results and showed that the cellulose membranes were chemically identical with cotton cellulose. In the brown algae, therefore, mannitol is probably the precursor of the cellulose.

\section{Laminaria cloustoni}

\section{The Laminariaceae}

In Fig. I the graphs for the stipe, the frond and the whole plant show that the cellulose content on the anhydrous basis exhibits two maxima and two minima in the year. Similar graphs have been obtained for several of the other constituents (Black, I948 a,b, I949) and for the diatom periodicity, and sometimes there is a correlation with the nutrient content of the water and the periods of rapid and slow growth (Black \& Dewar, 1949).

In March, when the new frond is forming, the cellulose is at a maximum of $5.76 \%$ in the frond and $10.27 \%$ in the stipe. From March to June/July a period of rapid growth occurs with an increase in the mannitol content while the cellulose content decreases. This may be due to the accumulation of mannitol in the whole plant or to elongation during rapid growth. From June to August/September during the period of slow growth, when the nutrients are absent from the sea water, the cellulose content increases again, while at the same time laminarin is also increasing (Black, I948a). In September, when the nutrients are again regenerated in the sea water, there is probably a second period of growth and a decrease in the cellulose content occurs. It would appear, therefore, that when the results are expressed on the anhydrous basis a correlation exists between the cellulose content and the periods of rapid and slow growth. When the results, however, are calculated on the wet basis (Fig. 2) two maxima are again recorded, one in February/March and the other from September to November. On the dry basis the cellulose content begins to fall in April and continues to fall until June; on the wet basis it is constant and at a minimum from April to June, due to the dry weight increasing with a rapid increase in mannitol. From June to November the cellulose on the wet basis increases while on the dry basis it begins to decrease in September, the increase in dry-weight content now being due to an increase in laminarin. A rapid decrease then occurs in December, the period of sporogenesis of this species, and this is probably accompanied by an increase in the uptake of water, as there is a considerable decrease in the dry-matter content both in 


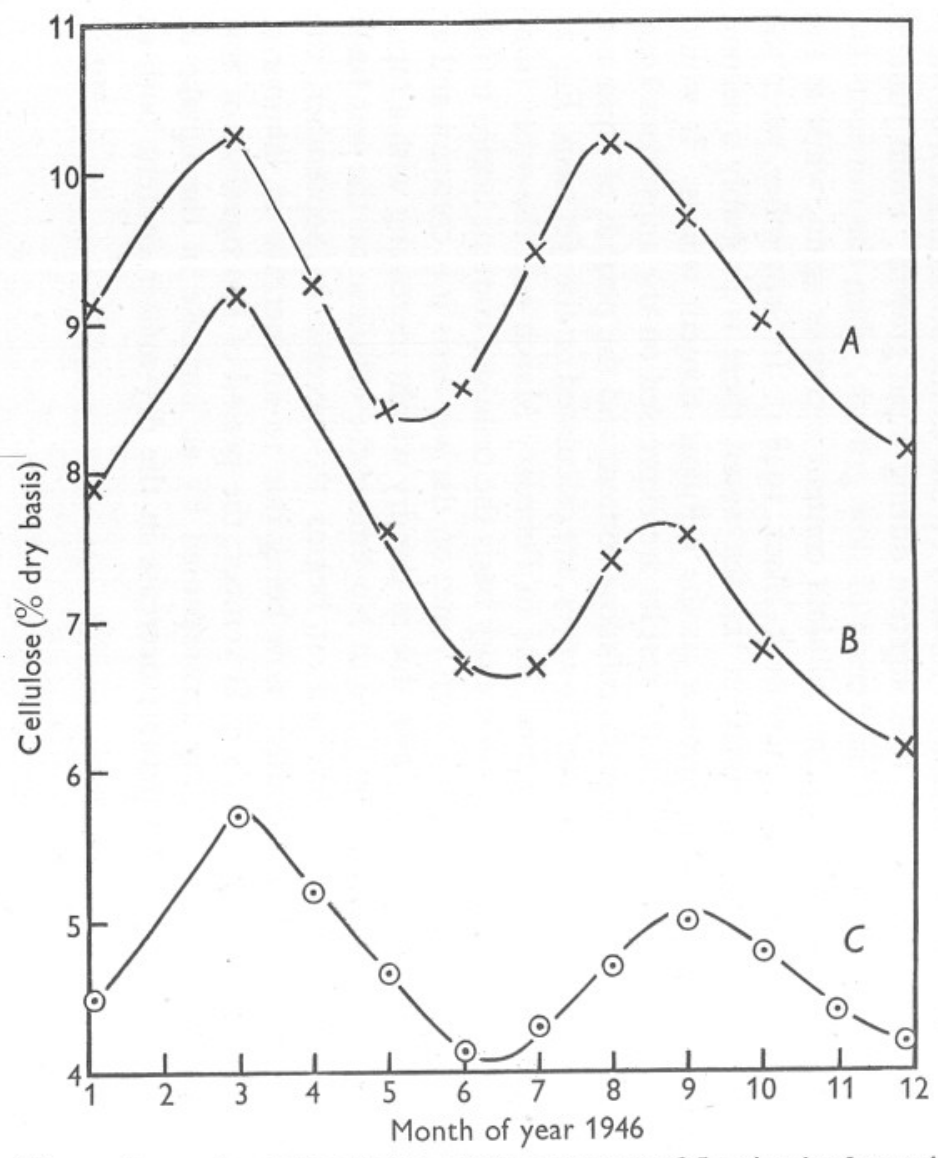

Fig. I. Seasonal variation in the cellulose content of Laminaria cloustoni (dry basis): $(A)$ in the stipes; $(B)$ in the whole plant; $(C)$ in the fronds.

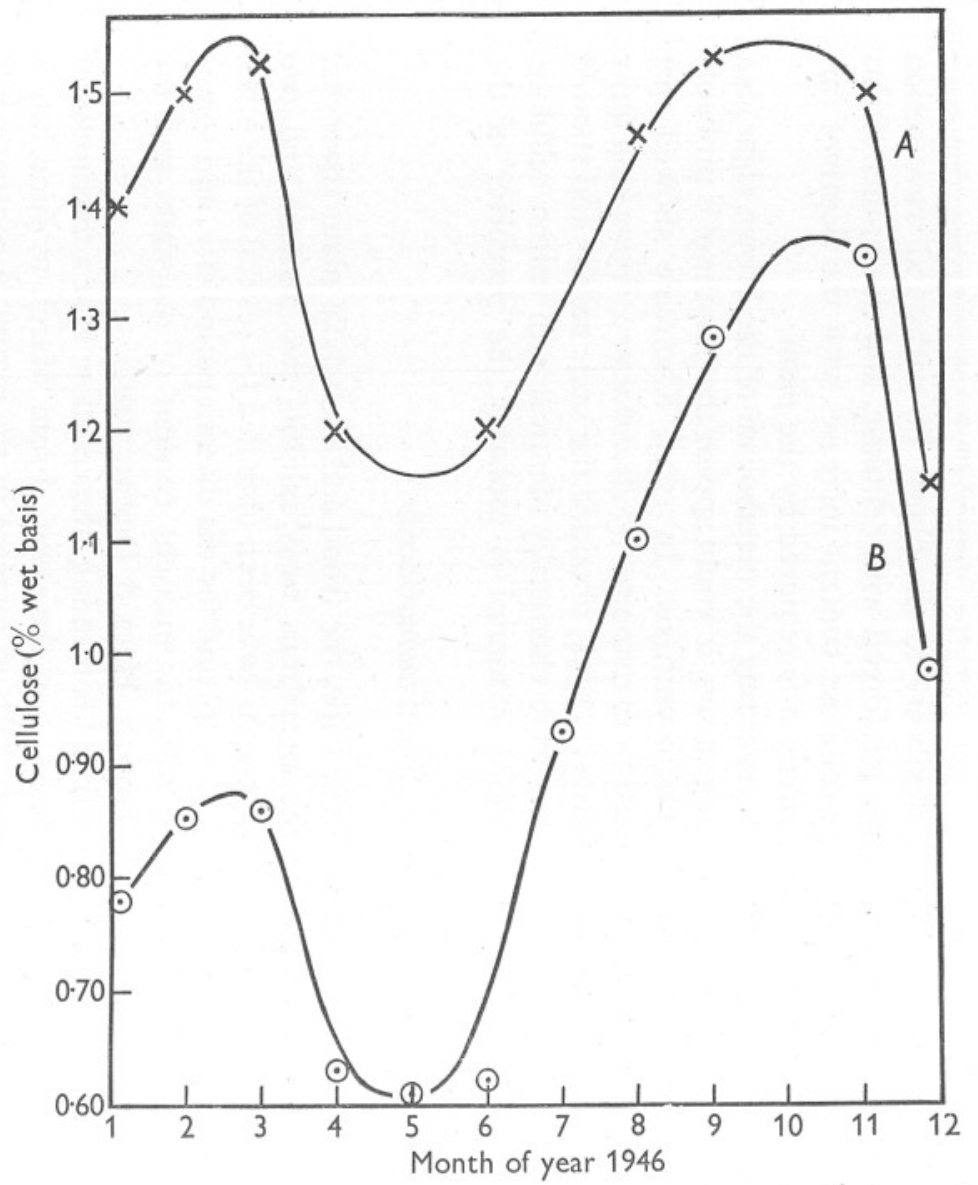

Fig. 2. Seasonal variation in the cellulose content of Laminaria cloustoni (wet basis): $(A)$ in the stipes; $(B)$ in the fronds. 
stipe and frond, which explains the rapid decrease on the wet basis while there is little change on the dry basis. On the wet basis, therefore, there would appear to be a correlation between the cellulose content and the reproductive cycle of the plant.

\section{Laminaria saccharina}

In this species the cellulose content (dry basis) of the frond $(4-5 \%$, Fig. 3) is of the same order of magnitude as that of L. cloustoni frond (Fig. I), but the stipes contain less cellulose $(7-8 \%)$ than those of L. cloustoni $(8 \cdot 5-10 \%)$. Considerably less seasonal variation occurs in this species, but despite this the two maxima are apparent in the year and occur at approximately the same time as those of L. cloustoni.

\section{Laminaria digitata.}

The cellulose content of this species (Fig. 4) undergoes a similar seasonal variation to that of $L$. saccharina, with the exception of the loch frond samples in which the variation is between 3 and $5 \%$. In general, however, the graphs are very similar and exhibit two maxima in the year and a distinct minimum in July.

The cellulose graphs on a wet basis for L. saccharina and L. digitata have been omitted. The only outstanding feature in both species is that the graphs for the open-sea samples show less seasonal variation $(0.5-0.7 \%)$ than those for the loch samples $(0.5-1 \cdot 0 \%)$. This is due to the marked seasonal variation in dry matter which occurs in the loch samples as the result of the accumulation of laminarin. This is in agreement, to a certain extent, with the theory that the cellulose content can be correlated with the periods of growth. At Atlantic Bridge the $L$. digitata frond grows to a length of $7-8 \mathrm{ft}$. (213-244 cm.), growth appears to continue throughout the summer and there is very little laminarin formed. The dry weight shows little change and there is no marked variation in the cellulose content. On the other hand, in Loch Melfort, the L. digitata frond only grows to a length of about $2-3 \mathrm{ft}$. (6I-9I cm.), laminarin accumulates and there is a marked increase in the dry-matter content. It appears, therefore, that laminarin is formed when photosynthesis can proceed, but some other factor is limiting growth.

\section{The Fucaceae}

With the exception of Fucus spiralis, which contains approximately $4.5 \%$ of cellulose (dry basis) throughout the year, there appears to be a correlation between the cellulose content of the Fucaceae and the depth of immersion of the species, the cellulose increasing from about $\mathrm{I} \%$ in Pelvetia canaliculata to $2-2.5 \%$ in Fucus serratus and F. vesiculosus. On the anhydrous basis the cellulose content of Pelvetia canaliculata, Ascophyllum nodosum and Fucus spiralis remains relatively constant throughout the year (Fig. 5). But when the results 


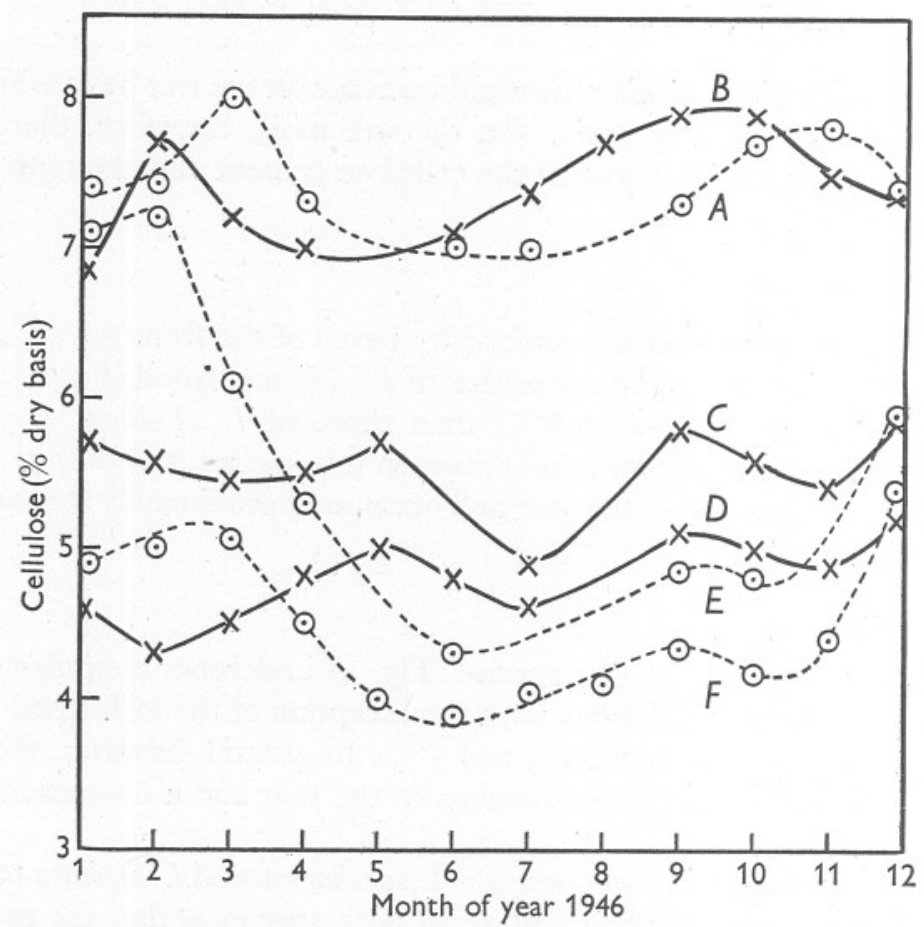

Fig. 3. Seasonal variation in the cellulose content of Laminaria saccharina (dry basis): $(A)$ in the open-sea stipes; $(B)$ in the loch stipes; $(C)$ in the loch whole plants; $(D)$ in the loch fronds; $(E)$ in the open-sea whole plants; $(F)$ in the open-sea fronds.

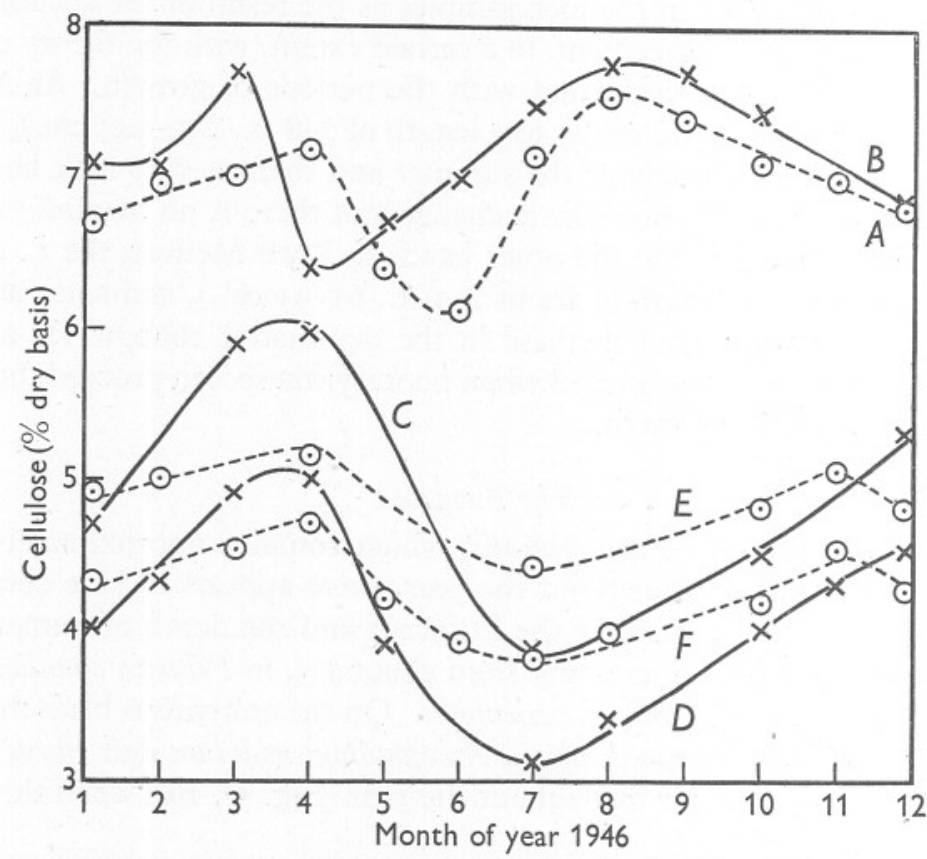

Fig. 4. Seasonal variation in the cellulose content of Laminaria digitata (dry basis): $(A)$ in the open-sea stipes; $(B)$ in the loch stipes; $(C)$ in the loch whole plants; $(D)$ in the loch fronds; $(E)$ in the open-sea whole plants; $(F)$ in the open-sea fronds. 


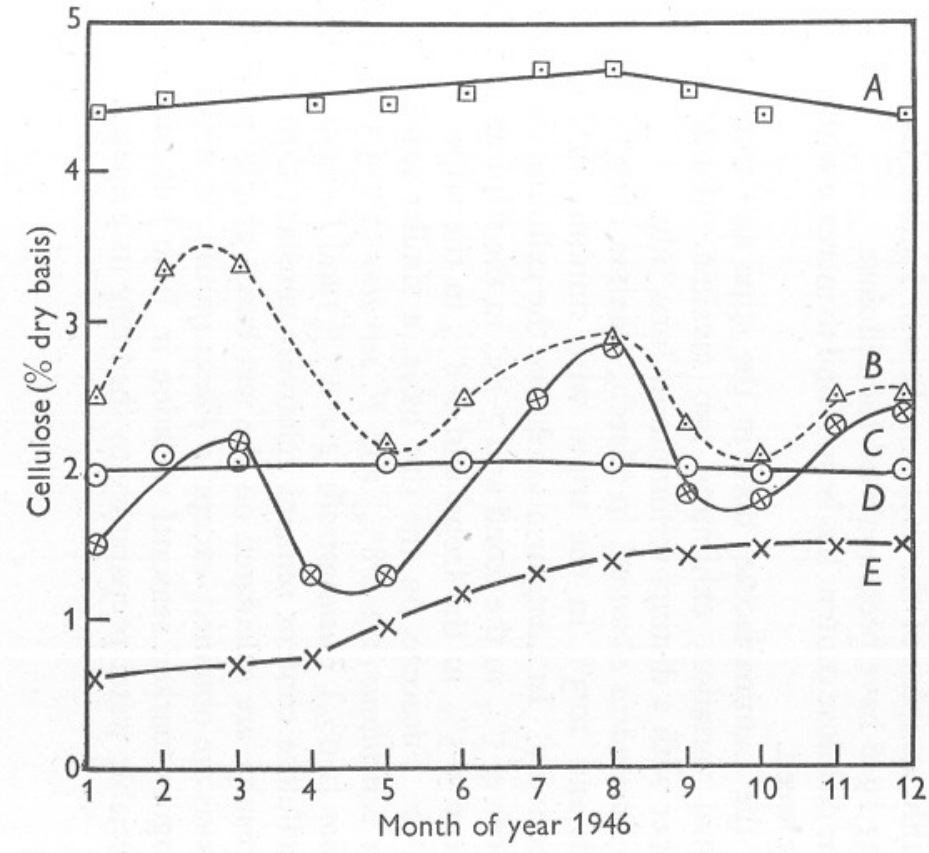

Fig. 5. Seasonal variation in the cellulose content of the Fucaceae (dry basis): (A) Fucus spiralis; $(B) F$. serratus; $(C) F$. vesiculosus; $(D)$ Ascophyllum nodosum; (E) Pelvetia canaliculata.

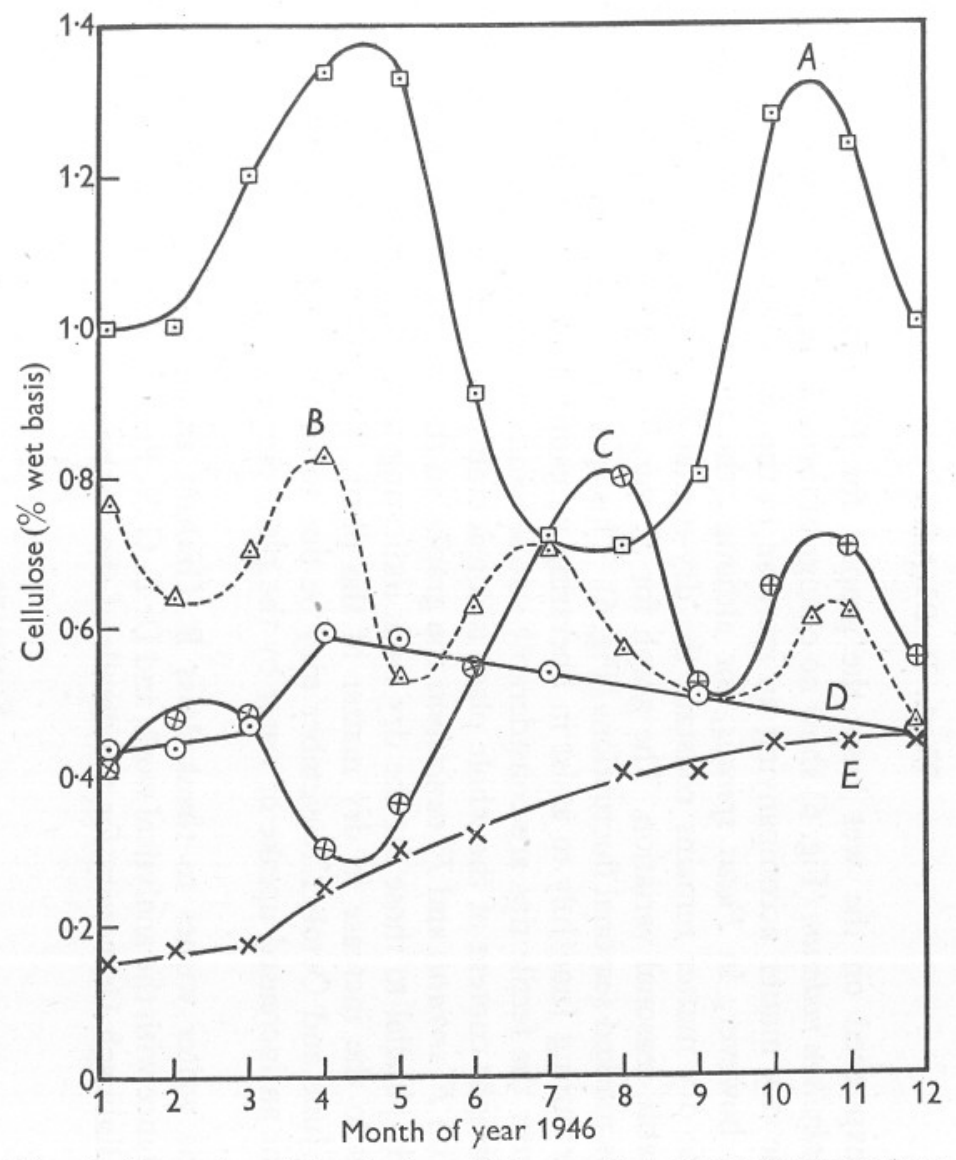

Fig. 6. Seasonal variation in the cellulose content of the Fucaceae (wet basis): (A) Fucus spiralis; $(B) F$. serratus; $(C) F$. vesiculosus; (D) Ascophyllum nodosum; (E) Pelvetia canaliculata. 
are expressed on the wet basis the graphs for Pelvetia canaliculata and Ascophyllum nodosum (Fig. 6) show no change of form, an increase in cellulose in the dry matter accompanying an increase in the dry weight. This is not true, however, in Fucus spiralis, for although the proportion of cellulose in the dry matter remains constant the dry-matter content undergoes considerable seasonal variation. The graph for $F$. spiralis (wet basis), therefore, shows marked seasonal fluctuations (Fig. 6). This species takes in a quantity of water during June/July to assist in liberating its gametes, and at this time of the year the fertile tips are considerably swollen and full of mucilage and the dry-weight content of the whole plant is considerably reduced.

With $F$. serratus and $F$. vesiculosus the graphs on the wet basis are approximately parallel to those for the dry basis indicating that the cellulose contributes to the increase in dry matter of the plant. The minima obtained in May/June and October/November may be due to rapid growth at that time and/or an increased uptake of water by the plant preparatory to sporing.

The writer wishes to thank Miss B. Graham and Mr W. Cornhill for assistance with the analytical work, and Dr E. G. V. Percival and Dr A. G. Ross of Edinburgh University for the details of the method.

\section{SUMMARY}

Monthly samples of the common British Laminariaceae and Fucaceae taken during I946 have been analysed for cellulose.

The cellulose content has been found to increase with the depth of immersion of the weed.

In the Laminariaceae, both in the stipe and frond it undergoes marked seasonal variation, exhibiting two maxima, March/April and September/ October with a distinct minimum in June/July.

In Laminaria cloustoni, in March, maxima of 5.7 (dry basis) occur in the fronds and $10.3 \%$ in the stipes with minima, in June, of 4.1 and $8.4 \%$ respectively. In Laminaria saccharina the cellulose content (dry basis) varies between $4-5 \%$ in the frond and $7-8 \%$ in the stipe and in Laminaria digitata between $3-5 \%$ in the frond and $6-8 \%$ in the stipe.

In the Fucaceae, on the dry basis, a similar seasonal variation occurs in Fucus vesiculosus $(\mathrm{I} \cdot 2-2 \cdot 8 \%$ ) and F. serratus (2. $\mathrm{I}-3 \cdot 5 \%$ ), but in Ascophyllum nodosum $(2 \cdot 0 \%)$, Fucus spiralis $(4 \cdot 4-4 \cdot 7 \%)$ and Pelvetia canaliculata (0.6-1.5\%) the cellulose content remains relatively constant throughout the year. When the results are calculated on the wet basis, graphs parallel to those for the dry basis are obtained, except in Fucus spiralis, in which the cellulose content undergoes marked seasonal variation in June/July, since this species takes in appreciable water preparatory to shedding its gametes. 


\section{REFERENCES}

Atsuki, K. \& Tomodo, Y., I926. Studies on seaweeds of Japan. First report on the chemical constitution of the Laminaria. Fourn. Soc. Chem. Ind. Fapan, Vol. 29, p. $132 \mathrm{~B}$.

Barsha, J. \& Hibbert, H., I934. Cellulose membrane from mannitol. Canadian fourn. Research, Vol. 10, pp. I70-9.

BLACK, W. A. P., I948a. Seasonal variation in the chemical constitution of some of the Laminariaceae common to Scotland. Fourn. Soc. Chem. Ind., Vol. 67, pp. I65-72.

- I948b. The seasonal variation in chemical composition of some of the littoral seaweeds common to Scotland. Part I. Ascophyllum nodosum. Fourn. Soc. Chem. Ind., Vol. 67, pp. 355-7.

- I949. Seasonal variation in chemical composition of some of the littoral seaweeds common to Scotland. Part II. F. serratus, F. vesiculosus, F. spiralis and Pelvetia canaliculata. Fourn. Soc. Chem. Ind., Vol. 68, pp. I83-9.

BLACK, W. A. P. \& DeWAR, E. T., I949. Correlation of some of the physical and chemical properties of the sea with the chemical constitution of the algae. Fourn. Mar. Biol. Assoc., Vol. xxvin, pp. 673-99.

Dillon, T. \& O’Tuama, T., I935. The cellulose of marine algae. Sci. Proc. Roy. Dublin Soc., Vol. 2I, pp. I47-52.

FRITSCH, F. E., I945. The Structure and Reproduction of the Algae. Vol. 2, p. 24.

KHouvine, Y., I933. Synthesis of cellulose from mannitol by Acetobacter xylinum. Comp. Rend. Acad. Sci., Paris, T. 196, pp. II44-6.

Kylin, K., I9I5. Biochemistry of sea algae. Ztschr. Physiol. Chem., Bd. 94, pp. 337425 .

Percival, E. G. V. \& Ross, A. G., I949. Marine algal cellulose. Fourn. Chem. Soc., pp. 304I-3.

RICARD, R., I93I. Nature and seasonal variation of carbohydrates in laminaria. Bull. Soc. Chim. Biol., Vol. 13, pp. 417-35.

Russel-Wells, B., I934. Cellulose in marine algae. Ann. Bot., Vol. 48, pp. 435-4I.

Stanford, E. C. C., I884. On algin. Fourn. Soc. Chem. Ind., Vol. 3, pp. 297-302.

VIel, G., I939. Sur les celluloses des algins. Comp. Rend. Acad. Sci., Paris, T. 208, pp. 532-4. 